\title{
The effects of native whey and $\alpha$-lactalbumin on the social and individual behaviour of C57BL/6J mice
}

\author{
O. Yu Vekovischeva ${ }^{1}$, K. Peuhkuri ${ }^{1}$, P. Bäckström ${ }^{1}$, N. Sihvola ${ }^{1}$, T. Pilvi ${ }^{2}$ and R. Korpela ${ }^{1 *}$ \\ ${ }^{1}$ Institute of Biomedicine, Pharmacology, Medical Nutrition Physiology, PO Box 63, FIN-O0014 University of Helsinki, \\ Finland \\ ${ }^{2}$ Valio Limited, PO Box 30, FI-O0039 Valio, Helsinki, Finland \\ (Submitted 10 April 2012 - Final revision received 16 November 2012 - Accepted 16 November 2012 - First published online 18 March 2013)
}

\begin{abstract}
Milk proteins are the main components of everyday feeding and demonstrate a promising potential to change the mental condition. However, the effects of milk proteins after prolonged use remain poorly understood. The aim of the present study was to compare the effects of two whey proteins ( $\alpha$-lactalbumin $(\alpha$-lac) and native whey) with casein on social and individual behaviour in mice. During a $30 \mathrm{~d}-$ long dietary intervention, male $\mathrm{C} 57 \mathrm{BL} / 6 \mathrm{~J}$ mice had ad libitum access to an experimental diet containing $17 \%$ (w/w) of one of three protein sources: $\alpha$-lac, native whey or casein. Mice had voluntary access to a running wheel. Social behaviour (group and resident-intruder activity) was tested at baseline and at the end of the intervention. Half of each dietary group was then withdrawn from the diet and running wheel for $7 \mathrm{~d}$, and social activity and individual behaviour tests (open field, elevated-plus maze, light-dark box and forced swimming) were performed, to evaluate anxiety and depression-like status. The study shows that the long-term ingestion of whey proteins may modulate behaviour when compared with casein. Diet enriched with $\alpha$-lac exhibited anxiolytic and antidepressive activities while the whey diet improved sociability. The differences between the diet groups were pronounced under the running wheel and the withdrawal of the experimental diet, suggesting that the beneficial effects of the milk proteins are clearer in stressful situations. Diet-induced behavioural changes remained visible for a week after feeding, which suggests that the proteins of the milk whey fraction have prolonged efficacy on the mental state of mice.
\end{abstract}

Key words: Casein: $\boldsymbol{\alpha}$-Lactalbumin: Native whey: Running wheels: Behaviour

Milk-derived proteins comprise two major fractions, casein and whey proteins, that differ in their amino acid composition, absorption and bioactive properties ${ }^{(1,2)}$. The neuroactive effects of milk proteins are mostly associated with the serotonin (5-hydroxytryptamine (5-HT)) system. The neurotransmitter 5 -HT is the main brain regulator of behaviour ${ }^{(2)}$ and its activity is dependent mostly on the availability of tryptophan (Trp), an essential amino acid precursor of 5-HT. The enzyme tryptophan hydroxylase converts Trp to 5-HT and is responsible for the concentration and availability of Trp in the blood that increases the synthesis and release of $5-\mathrm{HT}^{(2)}$.

The whey-derived protein $\alpha$-lactalbumin $(\alpha$-lac) is the main source of Trp from food ${ }^{(3)}$. A meal enriched with $\alpha$-lac showed beneficial anxiolytic-like effects on rats $^{(4)}$ and improved mood and cognition in stress-prone subjects after an acute intervention ${ }^{(5-8)}$. These changes were, however, not observed in healthy subjects, despite their increased plasma Trp concentration and ratio of Trp to other large neutral amino acids ${ }^{(9)}$. It has been shown that after a 1-week intake of a diet enriched with $\alpha$-lac, basal extracellular 5-HT levels were increasingly enhanced in rats, which reflects the increased serotonergic activity ${ }^{(4)}$. Although the dietaryinduced behavioural potential of whey-derived proteins appears promising, the effects of prolonged protein intake have been inadequately investigated. There are only a few studies on the effects of the chronic intake of milk protein on animal behaviour such as eating, grooming, resting, common activity $^{(10)}$ or energy intake ${ }^{(11)}$.

Contrary to whey proteins and their $\alpha$-lac component, casein, similar to many other food protein sources, has depleted Trp content when compared with large neutral amino acids. As a result, most of the previous studies have used a casein-containing diet as a control ${ }^{(7-9)}$. Thus, in the present study, we explored the beneficial effects of $\alpha$-lac-containing whey proteins such as $\alpha$-lac and native whey (whey) when compared with casein. In addition to $\alpha$-lac, native whey consists of $\beta$-lactoglobulin and lactoferrin, and may thus have behavioural effects beyond $\alpha-\operatorname{lac}^{(12)}$.

Abbreviations: 5-HT, 5-hydroxytryptamine; $\alpha$-lac, $\alpha$-lactalbumin; Trp, tryptophan.

*Corresponding author: Professor R. Korpela, fax +358 9191 25364, email riitta.korpela@helsinki.fi 
The aim of the present study was to determine the behavioural effects of long-term diets containing whey proteins ( $\alpha$-lac or whey) when compared with casein-induced effects in $\mathrm{C} 57 \mathrm{BL} / 6 \mathrm{~J}$ mice. Mouse housing was enriched with a running wheel to prevent any dairy diet-induced weight gain $^{(13)}$. It has been shown that voluntary physical exercise has an ability to activate central dopamine, noradrenaline and serotonin systems ${ }^{(14)}$, and to improve body composition in combination with amino acid food supplementation ${ }^{(15)}$. In the present study, mouse social behaviour was estimated after a $30 \mathrm{~d}$ protein intervention. Then, each diet group was subdivided into two subgroups: mice that continued to receive the experimental diet and access to the running wheel (enriched housing condition) and mice that returned to standard laboratory conditions (standard housing conditions) for $7 \mathrm{~d}$. Social and individual behaviour was estimated to specify the delayed effects of the prolonged diet.

\section{Materials and methods}

\section{Animals}

Adult C57BL/6J male mice (Charles River) of 2.5 months old were housed individually in standard plastic cages $(20 \times 34 \times 15 \mathrm{~cm})$ equipped with a wireless running wheel (ENV-044 model; Med Associates, Inc.), a sleeping shelter and a food cup. The animals lived under a $12 \mathrm{~h}$ daylight cycle with lights on at 06.00 hours under temperature- and humidity-controlled conditions. Running-wheel revolutions ( $n$ ) were recorded by Wi-Fi technology. Food consumption and body weight were measured every 2nd day. All procedures were approved by the National Animal Experiment Board and carried out in accordance with the guidelines for experimental animal care (ESLH-2008-01 090/Ym-23).

\section{Experimental diets}

For the present study, three experimental diets containing $17 \%(\mathrm{w} / \mathrm{w})$ protein were applied for $30 \mathrm{~d}$ after a $3 \mathrm{~d}$ habituation period during which mice were fed on a standard laboratory rodent chow (Harlan rodent diet 2018; Harlan BV). The nutritional content of the experimental diets is presented in Table 1 . The $\alpha$-lac group received a diet containing $\alpha$-lac $(92.7 \%(\mathrm{w} / \mathrm{w})$ of the final product; Valio Limited) and the whey group received a diet containing native whey (89.1\% $(\mathrm{w} / \mathrm{w})$ of the final product in which $23.9 \%$ was $\alpha$-lac and $65 \cdot 2 \%$ was $\beta$-lactoglobulin). Both whey proteins were mixed with a protein-free premix (commercial D09041501M powder; Research Diets, Inc.). As a control, we used a casein protein diet (commercial D12450BM powder; Research Diets, Inc.).

The protein powder was mixed with water to minimise powder spillage and to provide a uniform dough-like texture $^{(16)}$. A fresh chow portion was prepared every 4th day and kept at $-20^{\circ} \mathrm{C}$ before use. The fresh portion corresponding to the amount to cover normal ad libitum consumption $(6-7 \mathrm{~g})$ in mice ${ }^{(17)}$ was served every 2 nd day. Water was available ad libitum.
Table 1. Nutritional content of the experimental diets $(\mathrm{g} / 100 \mathrm{~g})$

\begin{tabular}{lrrr}
\hline & Casein & $\alpha$-Lac & Whey \\
\hline Energy (kJ) & 1577 & 1586 & 1586 \\
Carbohydrate (g) & 67.6 & 67.6 & 67.6 \\
Fibre (g) & 4.7 & 4.7 & 4.7 \\
Proteins (g) & & & \\
$\quad$ Casein & 19.0 & 0.0 & 0.0 \\
L-Cystine & 0.3 & 0.0 & 0.0 \\
$\quad \alpha$-Lac & 0.0 & 18.8 & 0.0 \\
Native whey & 0.0 & 0.0 & 18.8 \\
Fat (g) & 4.3 & 4.3 & 4.3 \\
Minerals (mg) & & & \\
Ca & 0.6 & 0.6 & 0.7 \\
P & 0.4 & 0.4 & 0.5 \\
K & 0.6 & 0.6 & 0.6 \\
Mg & 0.1 & 0.1 & 0.1 \\
Na & 0.1 & 0.3 & 0.1 \\
\hline
\end{tabular}

$\alpha$-Lac, $\alpha$-lactalbumin.

A food preference test was done on the 24 th day of dietary feeding after a $6 \mathrm{~h}$ food deprivation that was used to stimulate mouse exploratory activity ${ }^{(18)}$. The test was done in the environment of a T-maze apparatus ${ }^{(19)}$ that was made up of grey plastic and consisted of three arms $(50 \times 10 \mathrm{~cm})$ perpendicular to each other and with $15 \mathrm{~cm}$ walls. Each arm had a remote-controlled door that separated $12 \mathrm{~cm}$ compartments (in one arm) or $24 \mathrm{~cm}$ compartments (in two other arms). The animal was put in the central part (starting zone) of the apparatus for a $3 \mathrm{~min}$ habituation period when all doors were in the closed position so that the animal could only smell casein, $\alpha$-lac or whey food pieces ( $2 \mathrm{~g}$ pellet) through the narrow door slit $(5 \mathrm{~mm})$. Then, the doors were opened for the next $4 \mathrm{~min}$ and the animal could visit all compartments and taste the pellets.

The same sizes of nearest space about the pellets were specified on the arena template as pellet-related zones and were equidistant from the starting zone. The spatial disposition of the zones was changed randomly for every animal to exclude the spatial preference. Mouse track in the T-maze was observed by a video-tracking system with EthoVision Color-Pro 3.1 software (Noldus Information Technology) to estimate which zone was the most visited. Additionally, the food preference test included the group-housed C57BL/6J males of the same age ( $n$ 10) but using only a standard laboratory food (Harlan rodent diet 2018; Harlan BV).

\section{Study design}

The study design is illustrated in Fig. 1. Mice were divided into three equal groups according to the $K$-means analysis (SPSS version 20.0; SPSS Institute). Each group contained a similar number of animals having different ranks to equalise individual behavioural deviations of individual locomotor activity and body weight. Spontaneous horizontal locomotor activity was tested automatically for $30 \mathrm{~min}$ on the arena of individual plastic rectangular cages $(34 \times 19 \times 15 \mathrm{~cm})$ using a video-tracking system with EthoVision Color-Pro 3.1 software (Noldus Information Technology). After the ranking, mice were housed individually for $3 \mathrm{~d}$ habituation. Then, baseline social activity was estimated as described below. A wireless running wheel 


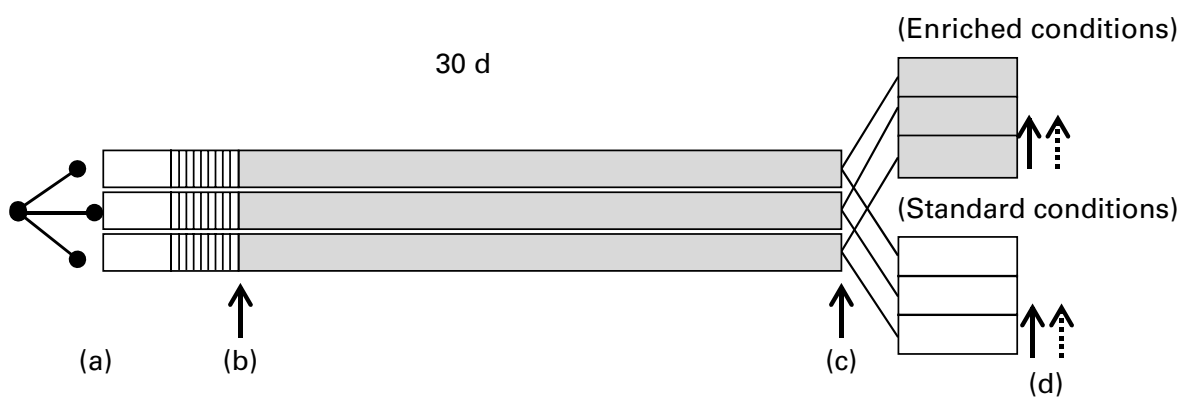

Fig. 1. Experimental design. (a) C57BL/6J mice were divided into three groups according to their weight and locomotor activity. The same protocol was used in all the diet groups ( $\alpha$-lactalbumin ( $\alpha$-lac), whey and casein). After $3 \mathrm{~d}$ of habituation in isolation, the running wheel was added to the cage. Social activity was tested at (b) baseline and (c) after the $30 \mathrm{~d}$ dietary feeding. (d) After further dividing the diet groups into two subgroups: social and individual behaviour as well as $6 \mathrm{~h}$ running-wheel activity were tested after $7 \mathrm{~d}$. $\square$, Standard diet, no running wheel (standard conditions); 四, standard diet, running wheel; $\square$, experimental diet ( $\alpha$-lac, whey or casein), running wheel (enriched conditions); $\uparrow$, social behaviour tests (group and resident-intruder tests); $\hat{\mathbf{A}}$, individual behaviour tests (light-dark box, open field, elevated-plus maze and forced swimming).

(ENV-044 model; Med Associates, Inc.) was added into the mouse home cage in $3 \mathrm{~d}$ before the dietary intervention was started for the next $30 \mathrm{~d}$.

After the $30 \mathrm{~d}$ dietary intervention, the social behaviour tests were repeated and each diet group ( $\alpha$-lac, whey and casein) was subdivided into two subgroups: mice that continued to use the diet and running wheel (enriched housing condition) and mice that returned to standard laboratory conditions (standard housing conditions) for $7 \mathrm{~d}$. We suggested that the $7 \mathrm{~d}$ post-intervention phase will be useful to estimate the delayed effects of the prolonged diet intervention. Standard laboratory conditions implied a return to the standard rodent chow (Harlan rodent diet 2018; Harlan BV) and no access to the running wheel. Thus, six groups were formed at this phase of the experiment.

After $7 \mathrm{~d}$, the social and individual behaviour tests were performed and the comparisons were made between the diet groups in the same conditions, but also within a diet group between the standard and enriched housing conditions. On the next day after the last behavioural test, mice in the standard housing conditions received access to the running wheel for $6 \mathrm{~h}$. Their running-wheel activity was compared with the activity that was developed by mice in the enriched housing conditions. The test was done to estimate whether removal of the running wheel was significant to increase its use after returning. Behavioural measurements were done automatically or video recorded. To provide a blind test of the observation, all behavioural samples (tracks or videos) were encoded to analyse them and opened only to perform a statistical analysis.

\section{Social behavioural tests}

Mouse social activity was evaluated among other males on a new territory (group social activity) as well as towards an unknown partner (male and female) on their own territory (resident-intruder test) ${ }^{(20)}$ for 9 min. Video-recorded samples were analysed subsequently by the data acquisition program Ethograph 2.06 (Ritec) according to the developed proto$\mathrm{col}^{(21)}$. Social activity tests, except the resident-intruder test towards an unknown female, were repeated three times: at baseline; after the dietary intervention; after the $7 \mathrm{~d}$ postintervention phase. The resident-intruder test towards an unknown female was done twice only: at baseline and after the dietary intervention.

The group test was performed to estimate mouse behaviour on the neutral territory of standard plastic cages $(20 \times 34 \times 15 \mathrm{~cm})$ towards other members of the temporarily organised group (three or four members). Observation was specified for five behavioural categories: (1) individual behaviour (any individual on-site behaviour, when contacts with other members are absent); (2) locomotor (any movements from site to site); (3) social contacts (any non-aggressive physical contact with the other group members); (4) consummate aggression (throws, fighting, biting and boxing); (5) defence (vertical upright, sideway stances, back defensive posture and freezing) ${ }^{(22)}$.

The resident-intruder test towards an unknown male was done on the territory of housing resident cage, where an unknown male was introduced. Resident behaviour was specified for five categories: (1) individual behaviour (any behaviour when contacts with the intruder were absent); (2) social contacts (any non-aggressive physical contacts with the intruder); (3) ambivalent aggression (demonstration of aggressive intentions: spinning about the intruder, tail rattling and digging of sawdust); (4) consummate aggression (throws, fighting, biting and boxing); (5) defence (vertical upright, sideway stances, back defensive posture and freezing) ${ }^{(22)}$.

The resident-intruder test towards an unknown receptive female was done in the resident territory where a female was introduced under a turned-over perforated metallic cylinder $(h=12 \mathrm{~cm}$, base $d=10 \mathrm{~cm}$; Etola Group) to protect the female from direct contact with the resident. The resident was allowed to sniff but not to mark or touch the female ${ }^{(23)}$. For this purpose, group-housing $\mathrm{C} 57 \mathrm{BL} / 6 \mathrm{~J}$ female peers on the oestrous phase of the oestrus cycle were used $(n 10)$. The phase of the oestrous cycle was determined as described previously $^{(24)}$ on the test day. The intruder behaviour was specified for eight categories: (1) individual behaviour (any behaviour demonstrating a great distance away (more than $3 \mathrm{~cm}$ ) from the cylinder); (2) sitting near the cylinder (less 
than $3 \mathrm{~cm}$ ); (3) running about the cylinder; (4) sniffing through the holes of the cylinder; (5) climbing on the cylinder; (6) sitting on top of the cylinder; (7) digging under the cylinder; (8) shifting or touching the cylinder by forepaws.

\section{Individual behavioural tests}

The test battery includes light-dark box, elevated-plus-maze and open-field tests ${ }^{(25,26)}$ that are based on the natural conflict between the tendencies to explore a new environment and to avoid potentially dangerous (open and lighted) areas ${ }^{(27)}$. Depression-like status was evaluated with a forced swimming test $^{(28)}$. The individual behaviour tests were performed after the $7 \mathrm{~d}$ post-intervention phase.

The light-dark box test was performed in a transparent plastic cage $(33 \times 55 \times 19 \mathrm{~cm})$ divided into open-lighted $(33 \times 33 \mathrm{~cm})$ and dark $(33 \times 22 \mathrm{~cm})$ parts that connect through a shelf. The mouse was placed in the centre of the openlighted area for $5 \mathrm{~min}$ and the duration and distance of the movement on the lighted area as well as the number of entries into the dark area were recorded automatically by a videotracking system (EthoVision; Noldus Information Technology).

The elevated-plus-maze test was performed the day after the light-dark box test. The maze apparatus was elevated to $50 \mathrm{~cm}$ above the floor level and consisted of the central start platform $(5 \times 5 \mathrm{~cm})$, from which two open arms $(5 \times 40 \mathrm{~cm}$ with a $0.7 \mathrm{~cm}$ margin) and two closed arms $(5 \times 40 \mathrm{~cm}$ with $20 \mathrm{~cm}$ walls) extended in opposite directions. Mouse track was recorded for $5 \mathrm{~min}$ by a video-tracking system (EthoVision) to measure the time spent in the open arms and in the protected zone (closed arms and start platform).

The open-field test was performed for 6 min immediately after the elevated-plus-maze test in a transparent plastic cage $(33 \times 55 \times 19 \mathrm{~cm})$ in which the floor was divided into fifteen squares $(11 \times 11 \mathrm{~cm})$ to specify the central and peripheral zones. The test was subdivided into two parts. Initially, the animal was put in the centre of the field for $3 \mathrm{~min}$ and then a yellow plastic ball ( $4 \mathrm{~cm}$ in diameter) was quickly installed in the central square. Mouse behaviour after the installation of the new object was observed for the next $3 \mathrm{~min}$. Videos were analysed subsequently using computer-assisted data acquisition software (Ethograph 2.06) according to the developed protocol ${ }^{(22,25)}$. Behaviour was specified as central and peripheral locomotor and non-locomotor behaviour; the new object exploration includes: sniffing; touching; manipulation by forepaws; freezing.

The forced swimming test was performed as the last test to evaluate mouse depression-like status that is based on the measure of immobility ${ }^{(28)}$. Mice were individually placed in a glass cylinder $(26.5 \mathrm{~cm}$ in height, $17 \mathrm{~cm}$ in diameter) filled with water $\left(22 \pm 1^{\circ} \mathrm{C}\right)$ to $16 \mathrm{~cm}$ for $6 \mathrm{~min}$. Mouse swimming behaviour (immobility events when the mouse froze; climbing, swimming and floating) was videotaped and measured by Ethograph 2.06 and EthoVision ${ }^{(29)}$.

\section{Statistical analysis}

Statistical analyses were conducted using the predictive analytics software PASW Statistics 20.0 (SPSS, Inc.). Primary comparisons of the results were done to compare the effects of the whey proteins with casein-induced effects under housing conditions. Multivariate ANOVA (two-way) followed by a Bonferroni or Kruskal-Wallis non-parametrical post boc test $(P<0.05)$ was used to analyse the data obtained from the social, food preference, light-dark box, elevated-plus-maze and forced swimming tests. If the tests were repeated several times (social tests), analysis for repeated measurements followed by a Bonferroni post hoc test $(P<0.05)$ was applied. $P$ values of less than 0.05 were considered to be statistically significant. Kaplan-Meier survival analysis with a MantelCox non-parametric test $(P<0.05)$ was used to analyse the probability of the first outcome of the element (latency of aggression and latency of immobility) that was based on the analysis of the time intervals ${ }^{(30)}$.

Behavioural elements specified for the analysis or combined group of the elements (category) received by Ethograph 2.06 were presented for statistical analysis in five measurements: total duration (sum of the duration of the element for the test); relative duration (ratio of the total element duration to the test duration); medial duration (ratio of the element duration to its total frequency); total frequency; relative frequency (ratio of the element frequency to the sum of all frequencies of the observed elements).

Numerous behavioural observations, as a matrix of probabilistic changes, require special statistical analysis of a higher level than mere descriptive statistics to evaluate all data as an integrated framework ${ }^{(31)}$. A discriminant function analysis, a multivariate statistical technique (based on Mahalanobis distance and a stepwise forward procedure), was used with the purpose to: (1) distinguish the dietary groups according to their behavioural function; (2) identify discriminate variables that contribute significantly to group differences; (3) determine an optimal manner for distinguishing between the groups; (4) determine unclassified individuals ${ }^{(32)}$. The analysis suggests that the hypothetical linear $n$-component functions $\left(F=d f c_{1} x v_{1}+\ldots+d f c_{\mathrm{n}} x v_{\mathrm{n}}\right)$ could be composed to describe a mouse behavioural profile. In this function coefficients $\left(d f_{c_{1}} x\right)$ were calculated by discriminant function analysis based on individual and social behavioural measurements and $v$ refers to behavioural elements.

\section{Results}

\section{Food preference}

All the tested mice spent more time in the $\alpha$-lac zone than in the casein zone $\left(F_{6,236}=2.61, P=0.02\right)$. Especially, the $\alpha$-lac- and whey-fed mice preferred the $\alpha$-lac zone when compared with the casein-fed ones (Kruskal-Wallis nonparametric test, $P=0.045)$. The whey zone was also preferred more than the casein zone, except for the whey-fed mice.

\section{Food consumption and weight gain}

All the dietary groups demonstrated identical food consumption $\left(F_{2,110}=3.05\right.$, NS; Fig. 2(a) $)$ while their body weight increased significantly $\left(F_{2,110}=8 \cdot 26, P<0 \cdot 0001\right.$; Fig. 2(b) : 

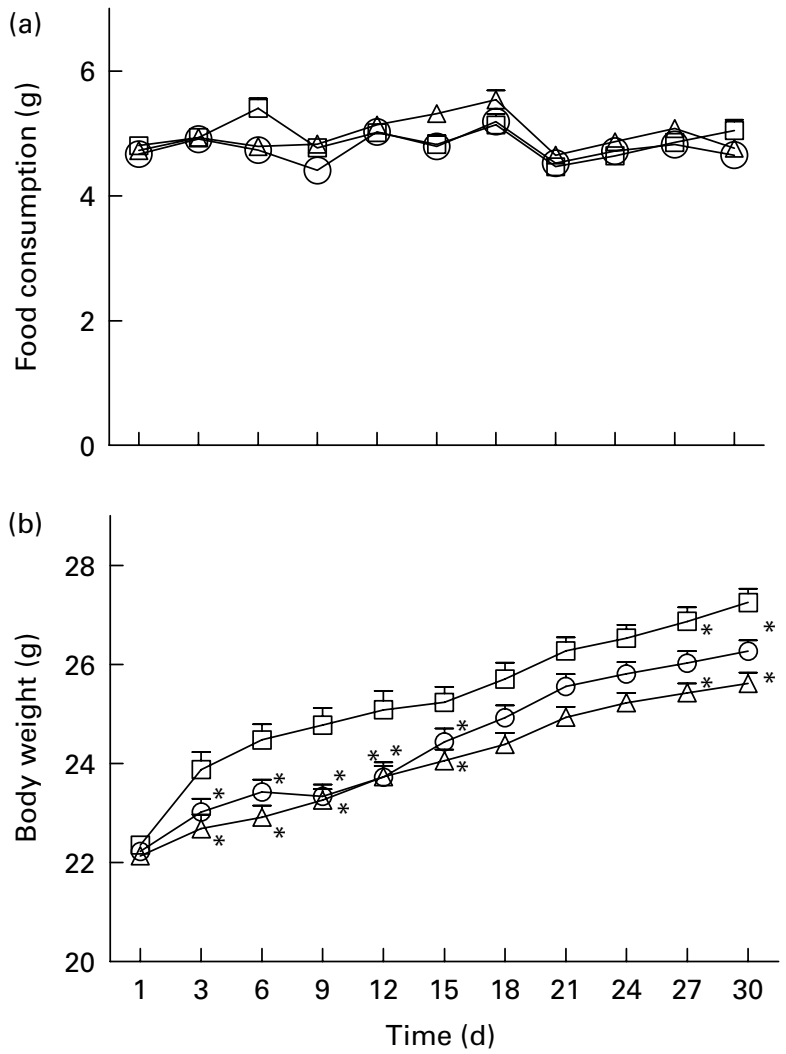

Fig. 2. (a) Food consumption and (b) body weight measured during the $30 \mathrm{~d}$ dietary feeding of casein ( $n 32, \square)$, whey $(n 42,--)$ and $\alpha$-lactalbumin ( $n 41$, $\triangle$ ) on every 3rd day. Values are means, with their standard errors represented by vertical bars. * Mean value was significantly different when compared with casein $(P<0.05$, Bonferroni post hoc test for repeated measurements). whey- and $\alpha$-lac-fed mice increased their body weight less than the casein-fed ones.

\section{Running-wheel activity}

Running-wheel activity between the dietary groups from day to day during the $30 \mathrm{~d}$ dietary intervention was similar $\left(F_{2,233}=1 \cdot 01\right.$, NS $)$ as well as its circadian distribution. The $6 \mathrm{~h}$ running-wheel test after the $7 \mathrm{~d}$ post-intervention revealed that the casein group under the standard housing conditions increased running-wheel activity when compared with casein-fed mice in the enriched conditions $\left(F_{1,38}=6 \cdot 81\right.$, $P=0 \cdot 014)$.

\section{Social behavioural tests}

At baseline, there were no differences in group social activity between the dietary groups. After the $30 \mathrm{~d}$ diet, whey-fed mice demonstrated more often non-aggressive contacts (relative frequency: $F_{2,39}=4.74, P=0.015$ ), individual behaviour (relative frequency: $F_{2,39}=4.95, P=0.012$ ) and locomotor behaviour (relative frequency: $F_{2,39}=4.70, P=0.015$ ) than the casein and $\alpha$-lac groups. Whey-fed mice changed their behaviour more often, suggesting that they were more dynamic. There were no differences in aggression behaviour, which was observed in $29 \%$ of $\alpha$-lac- and whey-fed mice and in $58 \%$ of casein-fed mice.

After the $7 \mathrm{~d}$ post-intervention phase, no differences were found in the enriched conditions between the diet groups (Table 2). In the standard conditions, the group on the $\alpha$-lac

Table 2. Social group behaviour of mice in the temporarily organised groups after the $7 \mathrm{~d}$ post-intervention in the different conditions (Mean values with their standard errors)

\begin{tabular}{|c|c|c|c|c|c|c|c|c|c|c|c|c|}
\hline \multirow[b]{3}{*}{ Behaviour } & \multicolumn{6}{|c|}{ Enriched conditions } & \multicolumn{6}{|c|}{ Standard conditions } \\
\hline & \multicolumn{2}{|c|}{ Casein } & \multicolumn{2}{|c|}{$\alpha$-Lac } & \multicolumn{2}{|c|}{ Whey } & \multicolumn{2}{|c|}{ Post-casein } & \multicolumn{2}{|c|}{ Post- $\alpha$-lac } & \multicolumn{2}{|c|}{ Post-whey } \\
\hline & Mean & SEM & Mean & SEM & Mean & SEM & Mean & SEM & Mean & SEM & Mean & SEM \\
\hline \multicolumn{13}{|l|}{ Individual } \\
\hline Relative duration & $25 \cdot 9$ & $2 \cdot 9$ & $25 \cdot 4$ & $2 \cdot 7$ & $28 \cdot 3$ & $2 \cdot 7$ & $23 \cdot 6$ & $2 \cdot 9$ & 32.5 & $2 \cdot 7$ & $31 \cdot 2$ & $2 \cdot 7$ \\
\hline Medial duration & $2 \cdot 1$ & 0.3 & 1.8 & 0.2 & $2 \cdot 1$ & 0.2 & 2 & 0.3 & $3 \cdot 1^{*} \dagger \ddagger$ & 0.2 & 2 & 0.2 \\
\hline Relative frequency & 0.6 & 0.1 & 0.7 & 0.1 & 0.7 & 0.1 & 0.6 & 0.1 & 0.6 & 0.1 & 0.8 & 0.1 \\
\hline \multicolumn{13}{|l|}{ Locomotor } \\
\hline Relative duration & $11 \cdot 3$ & 1.6 & $10 \cdot 1$ & $1 \cdot 1$ & $12 \cdot 3$ & $1 \cdot 1$ & $11 \cdot 2$ & 1.6 & $10 \cdot 3$ & $1 \cdot 1$ & 12 & $1 \cdot 1$ \\
\hline Medial duration & 0.7 & 0.5 & 0.6 & 0.5 & 0.7 & 0.1 & 0.7 & 0.5 & $0.8^{\star}$ & 0.5 & 0.6 & 0.1 \\
\hline Relative frequency & 0.8 & 0.1 & 0.8 & 0.1 & 0.9 & 0.1 & 0.8 & 0.1 & 0.7 & $0 \cdot 1$ & 0.9 & 0.1 \\
\hline \multicolumn{13}{|c|}{ Non-aggressive contacts } \\
\hline Relative duration & 31.7 & 3.8 & 38.9 & 3.5 & 33.5 & 3.5 & 36 & 3.8 & $20 \cdot 6^{*} \dagger$ & 3.5 & $27 \cdot 9$ & 3.5 \\
\hline Medial duration & 4 & 0.5 & $4 \cdot 1$ & 0.4 & 3.5 & 0.4 & $4 \cdot 1$ & 0.5 & $2 \cdot 7$ & 0.4 & $2 \cdot 8$ & 0.4 \\
\hline Relative frequency & 0.4 & 0 & 0.5 & 0 & 0.5 & 0 & 0.4 & 0 & $0.4^{\star} \ddagger$ & 0 & 0.5 & 0 \\
\hline \multicolumn{13}{|c|}{ Consummate aggression } \\
\hline Relative duration & 5.6 & 1.7 & 0.5 & 1.6 & 0.8 & 1.6 & $4 \cdot 1$ & 1.7 & $4 \cdot 8$ & 1.6 & 3.7 & 1.6 \\
\hline Medial duration & $6 \cdot 7$ & 1.4 & 1.5 & $1 \cdot 3$ & 1.4 & $1 \cdot 3$ & $2 \cdot 1$ & 1.4 & $2 \cdot 1$ & $1 \cdot 3$ & $3 \cdot 1$ & 1.3 \\
\hline Relative frequency & 0 & 0 & 0 & 0 & 0 & 0 & 0.1 & 0 & 0.1 & 0 & 0 & 0 \\
\hline \multicolumn{13}{|l|}{ Defence } \\
\hline Relative duration & 0.2 & 1.6 & 0 & 1.5 & 0.1 & 1.5 & 0.1 & 1.6 & $6 \cdot 7$ & 1.5 & 0 & 1.5 \\
\hline Medial duration & 1.5 & 0.6 & 0.1 & 0.6 & 0.3 & 0.6 & 0.2 & 0.6 & $2 \cdot 2^{*} \ddagger$ & 0.6 & 0.2 & 0.6 \\
\hline Relative frequency & 0 & 0 & 0 & 0 & 0 & 0 & 0 & 0 & $0.1^{*} \dagger$ & 0 & 0 & 0 \\
\hline
\end{tabular}

$\alpha$-Lac, $\alpha$-lactalbumin.

* Mean values were significantly different between the enriched and standard conditions for the same diet group $(P<0.05)$

$\dagger$ Mean values were significantly different compared with the casein group $(P<0.05)$.

$\ddagger$ Mean values were significantly different compared with the whey group within the same conditions $(P<0.05)$. 
diet showed low non-aggressive social activity (relative duration: $F_{2,39}=4 \cdot 79, P=0 \cdot 015$ ), but longer periods of individual (medial duration: $F_{2,39}=5.84, \quad P=0.015$ ), locomotor (medial duration: $F_{2,39}=4.73, \quad P=0.015$ ) and defensive (medial duration: $F_{2,39}=4.42, P=0.020$ ) behaviour than the casein group. Whey-fed mice in the standard conditions started a fight later than casein-fed mice (Kaplan-Meier survival analysis: log-rank Mantel-Cox 5.42, $P=0.020$; Fig. 3).

When comparing the housing conditions, $\alpha$-lac-fed mice only contacted less with the other group members in the standard conditions (relative frequency: $F_{2,39}=3 \cdot 48, P=0 \cdot 42$ ), but more often demonstrated agonistic behaviour (defensive behaviour: $F_{2,39}=4.84, P=0.014$ and aggressive behaviour: $\left.F_{2,39}=7.05, \quad P=0.012\right)$ than their peers in the enriched
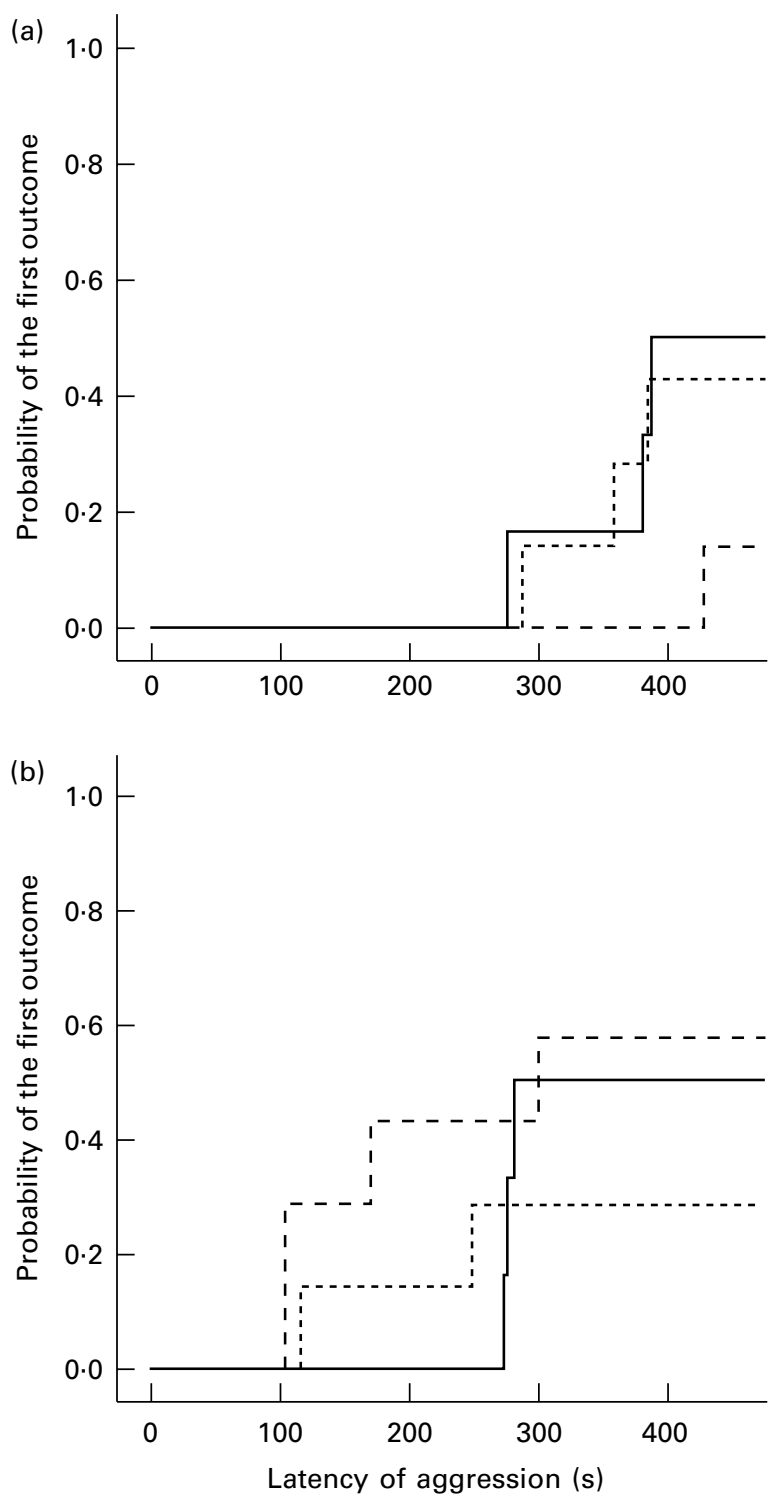

Fig. 3. Probability of the first outcome of aggression in the group tests by the Kaplan-Meier survival analysis. The results are presented for the different environmental conditions: (a) enriched conditions (casein, $n$ 14; whey, $n 19$ $\alpha$-lactalbumin ( $\alpha$-lac), $n$ 19) and (b) standard conditions (casein, $n$ 17; whey, $n$ 23; $\alpha$-lac, $n$ 22). (+) Latency was censored by the test time (540 s). Casein; -....., whey; --- , $\alpha$-lac. conditions. Kaplan-Meier analysis showed that $\alpha$-lac-fed mice in the standard conditions started a fight more quickly than their peers in the enriched conditions (log-rank MantelCox 8.06, $P=0.005)$.

The resident-intruder test towards an unknown male was repeated three times. The baseline activity of the resident after the short-term $3 \mathrm{~d}$ social isolation did not contain any aggressive interactions. After $30 \mathrm{~d}$ isolation by the dietary intervention, aggressive behaviour was similar in all the diet groups: only $58 \%$ of casein-fed mice and $57 \%$ of $\alpha$-lac- and whey-fed mice showed aggressive behaviour. Also, no dietspecific differences were found after the $7 \mathrm{~d}$ post-intervention period. However, aggressive demonstrations were observed in more animals ( $\chi^{2}$ test, $\left.P=0 \cdot 016\right)$ under the enriched conditions (64, 63 and $73 \%$ of casein-, $\alpha$-lac- and whey-fed mice, respectively) than after the standard conditions (16, 45 and $36 \%$ of casein-, $\alpha$-lac- and whey-fed mice, respectively). Despite the varying level of aggression under the housing conditions, any diet-specific effects remained unclear.

The resident-intruder test towards an unknown female was repeated two times. At baseline, all males demonstrated a similar concerned behaviour towards the female hidden under the cylinder. In the second test, after the $30 \mathrm{~d}$ dietary intervention, whey-fed mice demonstrated more activity towards the female than the casein-fed ones. Thus, whey-fed mice dug under the cylinder longer (total duration: $F_{2,39}=3 \cdot 48$, $P=0.041$ and relative frequency: $\left.F_{2,39}=4 \cdot 25, P=0 \cdot 022\right)$.

\section{Individual behavioural tests}

The results of the individual behaviour tests, performed after the $7 \mathrm{~d}$ post-intervention phase, are presented in Table 3 . In the enriched conditions, the light-dark box test showed that $\alpha$-lac-fed mice spent less time and were less mobile in the light compartment than casein-fed mice $\left(F_{2,73}=5 \cdot 65, P=0.005\right.$ and $F_{2,73}=3.88, \quad P=0.03$, respectively). However, in the standard conditions, all mice spent more time in the light compartment than their peers under the enriched conditions $\left(F_{1,73}=36 \cdot 34, \quad P<0 \cdot 0001\right)$, and $\alpha$-lac-fed mice also moved more actively in the light compartment $\left(F_{1,73}=12 \cdot 89, P=0 \cdot 001\right)$.

The elevated-plus-maze test revealed that, in the enriched conditions, the $\alpha$-lac and whey groups overcame longer distance in the protected zones (closed arms and start square) when compared with the casein group in the same conditions and when compared with their peers in the standard conditions $\left(F_{2,73}=4.14, \quad P=0.027 ; \quad F_{1,73}=22.46, P<0.0001\right.$ for both diet and housing conditions).

In the open-field test, diet- and housing-related effects were found after the new object was installed (for the second 3 min interval). $\alpha$-Lac-fed mice in the standard conditions moved more actively on the periphery of the field $\left(F_{1,71}=11.48, P<0.0001\right.$ and $F_{1,71}=9.89, P=0.002$ for total duration_2 and total frequency_2, respectively) and on the centre $\left(F_{1,71}=5.83, P=0.0019\right.$ and $\left.F_{1,71}=10 \cdot 24, P=0.002\right)$ than their peers in the enriched conditions. At the same time, whey-fed mice in the standard conditions were more mobile on the centre $\left(F_{1,71}=9 \cdot 89, \quad P=0.0002\right.$ and $F_{1,71}=10 \cdot 24$, $P=0 \cdot 002)$. 
Table 3. Individual mouse running-wheel activity and behaviour in tests assessing anxiety and depression-like status in the $7 \mathrm{~d}$ post-intervention phase*

(Mean values with their standard errors)

\begin{tabular}{|c|c|c|c|c|c|c|c|c|c|c|c|c|}
\hline & \multicolumn{6}{|c|}{ Enriched conditions } & \multicolumn{6}{|c|}{ Standard conditions } \\
\hline & \multicolumn{2}{|c|}{ Casein } & \multicolumn{2}{|c|}{$\alpha$-Lac } & \multicolumn{2}{|c|}{ Whey } & \multicolumn{2}{|c|}{ Post-casein } & \multicolumn{2}{|c|}{ Post- $\alpha$-lac } & \multicolumn{2}{|c|}{ Post-whey } \\
\hline & Mean & SEM & Mean & SEM & Mean & SEM & Mean & SEM & Mean & SEM & Mean & SEM \\
\hline \multicolumn{13}{|l|}{ Running wheel } \\
\hline $6 \mathrm{~h}$ activity after deprivation $(n)$ & 2947 & 1978 & 7333 & 1832 & 9556 & 1832 & $9404 \dagger$ & 2167 & 11618 & 1832 & 11061 & 1832 \\
\hline \multicolumn{13}{|l|}{ Light-dark box } \\
\hline Time spent in light (s) & 187 & 21 & $124 \ddagger$ & 17 & 178 & 18 & $275 \dagger$ & 18 & $224 \dagger$ & 17 & $251 \dagger$ & 15 \\
\hline Mobility in light (s) & 154 & 15 & $102 \ddagger$ & 13 & 133 & 13 & 184 & 13 & $162 \dagger$ & 11 & 155 & 11 \\
\hline \multicolumn{13}{|l|}{ Elevated-plus maze } \\
\hline Distance in protected area $(\mathrm{mm})$ & 997 & 92 & $1235 \ddagger$ & 75 & $1235 \ddagger$ & 75 & 758 & 78 & $961 \dagger$ & 67 & $864 \dagger$ & 65 \\
\hline \multicolumn{13}{|l|}{ Open field } \\
\hline \multicolumn{13}{|l|}{ Peripheral locomotor } \\
\hline Total duration & $17 \cdot 2$ & $3 \cdot 7$ & $18 \cdot 6$ & 3.0 & $18 \cdot 2$ & 3.0 & $25 \cdot 7$ & $3 \cdot 2$ & $30.5 \dagger$ & $2 \cdot 9$ & 23.5 & $2 \cdot 6$ \\
\hline Total frequency & $18 \cdot 6$ & 3.4 & $19 \cdot 9$ & $2 \cdot 8$ & $19 \cdot 3$ & $2 \cdot 8$ & $21 \cdot 6$ & 2.9 & $30.5 \dagger$ & $2 \cdot 6$ & $22 \cdot 3$ & $2 \cdot 4$ \\
\hline \multicolumn{13}{|l|}{ Central locomotion } \\
\hline Total duration & 1.5 & 1.0 & $2 \cdot 2$ & 0.8 & 1.3 & 0.8 & $2 \cdot 5$ & 0.8 & $5 \cdot 1 \dagger$ & 0.8 & $3 \cdot 7 \dagger$ & 0.7 \\
\hline Total frequency & 1.6 & 1.0 & 2.4 & 0.8 & 1.7 & 0.8 & $3 \cdot 1$ & 0.9 & $5.2 \dagger$ & 0.8 & $4 \cdot 1 \dagger$ & 0.7 \\
\hline \multicolumn{13}{|l|}{ Contact with the new object } \\
\hline Total duration & 3.4 & 1.5 & $3 \cdot 1$ & $1 \cdot 2$ & 3.8 & $1 \cdot 2$ & 3.8 & $1 \cdot 3$ & $8 \cdot 8 \dagger \ddagger$ & $1 \cdot 2$ & $7.6 \dagger$ & 1.7 \\
\hline Total frequency & 3.5 & 1.3 & 3.3 & 1.1 & 3.6 & $1 \cdot 1$ & $5 \cdot 2$ & $1 \cdot 1$ & $7.4 \dagger$ & 1.0 & $6 \cdot 3$ & 0.9 \\
\hline \multicolumn{13}{|l|}{ Freezing by the new object } \\
\hline Total duration & 8.7 & $2 \cdot 6$ & $15.4 \S$ & $2 \cdot 1$ & 4.9 & $2 \cdot 1$ & 13.6 & $2 \cdot 2$ & $6 \cdot 7 \dagger$ & $2 \cdot 0$ & $9 \cdot 8$ & 1.8 \\
\hline Total frequency & $5 \cdot 8$ & $1 \cdot 0$ & $8.8 \S$ & 0.8 & 3.6 & 0.8 & $9.5 \dagger$ & 0.9 & 3.8 & 0.8 & 4.8 & 0.7 \\
\hline \multicolumn{13}{|l|}{ Forced swimming } \\
\hline Immobility latency (s) & $61 \cdot 1$ & $10 \cdot 7$ & $61 \cdot 2 \S$ & 4.9 & 40.5 & $6 \cdot 0$ & $116 \cdot 4 \dagger$ & 11.6 & $101 \cdot 0+\S$ & 13.9 & $79 \cdot 0 \dagger \ddagger$ & 8.0 \\
\hline
\end{tabular}

$\alpha$-Lac, $\alpha$-lactalbumin.

*Behavioural measurements are presented for the casein, $\alpha$-lac and whey groups that were exposed to the experimental diet and had access to the running wheel or were exposed to the standard diet and had no access to the running wheel.

† Mean values were significantly different between the enriched and standard conditions for the same diet group $(P<0.05)$.

$\ddagger$ Mean values were significantly different compared with the casein group $(P<0.05)$.

$\S$ Mean values were significantly different compared with the whey group within the same conditions $(P<0.05)$.

The time to explore the new object was longer both in $\alpha$-lac- and whey-fed mice in the standard conditions when compared with the enriched conditions (total duration: $\left.F_{1,71}=10.35, P=0.002\right)$. In the standard conditions, $\alpha$-lac-fed mice also contacted with the new object longer (total duration: $\left.F_{1,71}=10 \cdot 22, P=0.002\right)$ and demonstrated less and shorter time of 'freezing' (total duration: $F_{2,71}=6.86, P=0.002$ and total frequency: $F_{2,71}=13 \cdot 46, P<0 \cdot 0001$, respectively) than their peers in the enriched conditions. On the contrary, the casein group demonstrated 'freezing' more often after the standard conditions than after the enriched conditions (total frequency_2: $\left.F_{2,71}=13 \cdot 59, P<0 \cdot 0001\right)$.

In the forced swimming test, whey-fed mice stopped swimming more quickly than $\alpha$-lac-fed mice (log-rank Mantel-Cox 3.96, $P=0.047$ due to the Kaplan-Meier survival analysis) under the enriched conditions. They also ceased swimming more quickly than casein- and $\alpha$-lac-fed mice (log-rank Mantel-Cox 5.77, $P=0.016$ and log-rank Mantel-Cox 4.62, $P=0.032$, respectively, due to the Kaplan-Meier survival analysis) under the standard conditions. Swimming was observed to be longer in all mice after the standard conditions than in the enriched conditions $\left(F_{2,73}=4 \cdot 32, P=0 \cdot 017\right)$.

\section{Discriminant function analysis}

A discriminant function analysis was done in order to estimate all data as an integrated framework. Mice under the enriched conditions were classified correctly $(P<0.05)$ according to the diet received in $93.8 \%$ of the original grouped cases and in $84.4 \%$ of the cross-validated grouped cases (Fig. 4(a)). Standardised canonical discriminant function coefficients are illustrated in Table 4 for behavioural variables that contributed significantly to group differences. A small number of casein and $\alpha$-lac animals (12 and 8.3\%, respectively) were classified as were whey-fed mice. In turn, only $75 \%$ of whey-fed mice were classified correctly: 8.3 and $16.7 \%$ of the animals were classified similar to casein- and $\alpha$-lac-fed mice, respectively.

After the standard conditions for $7 \mathrm{~d}$, mice were classified correctly $(P<0.05)$ by diets in $97.6 \%$ of the original grouped cases and in $90.5 \%$ of the cross-validated grouped cases (Fig. 4(b)). All (100\%) of the casein animals were classified correctly, whereas $6.3 \%$ of whey males were classified as $\alpha$-lac-fed mice, and $20 \%$ of $\alpha$-lac males were classified as casein- (13.3\%) and whey-fed (6.7\%) mice. Discrimination of mice between the conditions within the same diet group was done successfully $(P<0.05)$ for 100,96 and $100 \%$ of the casein, $\alpha$-lac and whey groups, respectively, which suggests that the housing conditions to modulate mouse behaviour were important.

\section{Discussion}

The effects of $30 \mathrm{~d}$ milk protein-containing diets were studied in $\mathrm{C} 57 \mathrm{BL} / 6 \mathrm{~J}$ mice to determine whether the long-term intake 

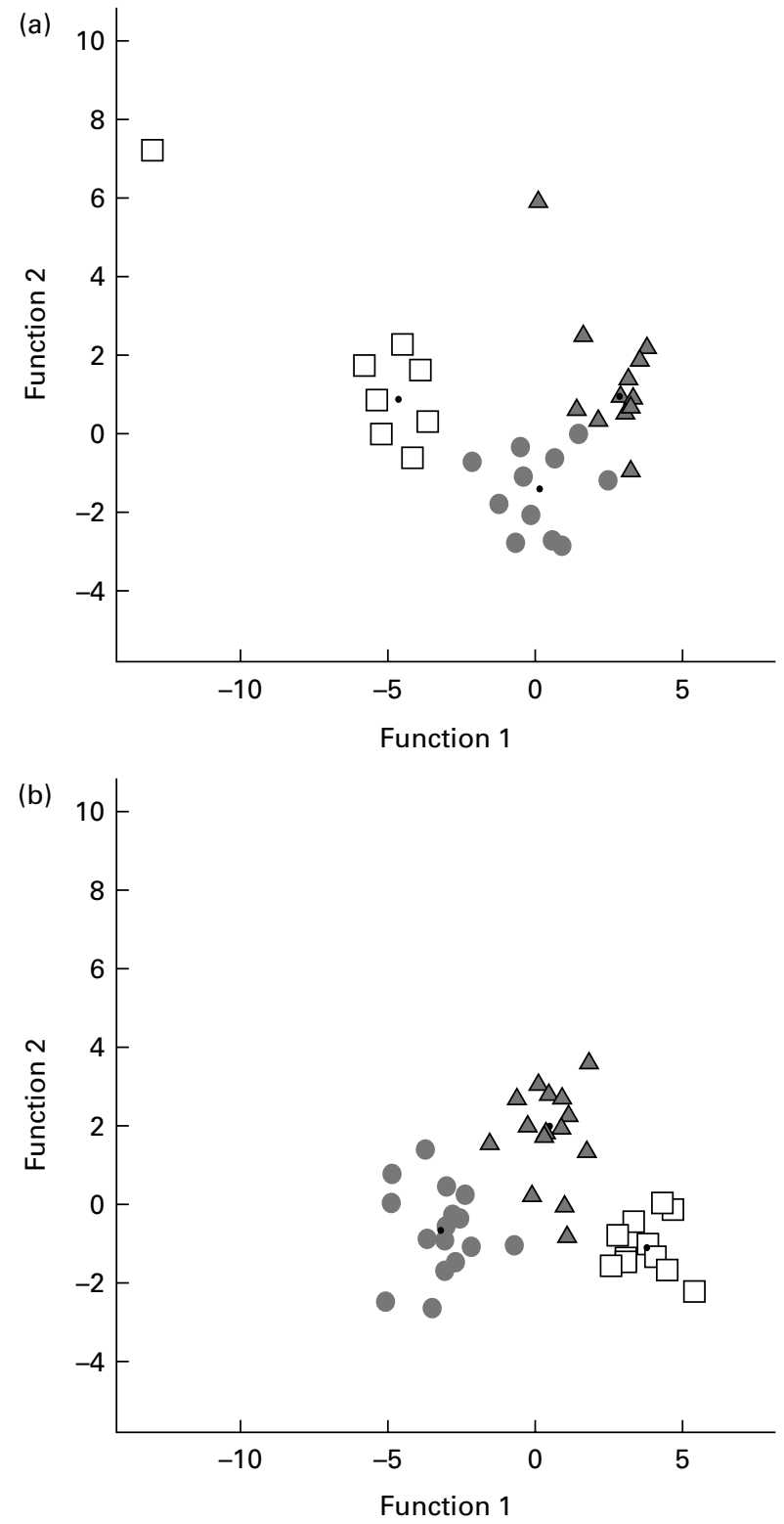

Fig. 4. Plot of the behavioural profiles based on the discriminant function analysis of the groups after the $7 d$ environmental changes: (a) enriched conditions or (b) standard conditions. $\square$, Casein; $\Delta, \alpha$-lactalbumin; $\bullet$, whey.

of milk protein (whey proteins $v$. casein) affects social and individual behaviour ${ }^{(33)}$. The behavioural efficacy of milk proteins was also estimated $7 \mathrm{~d}$ after the diet intervention when the animals were returned to standard laboratory conditions. Physical status as a main determinant of behavioural manifestations ${ }^{(10)}$ was taken care by the regular food consumption and body-weight measurements.

We found that both proteins of the milk-whey fraction, $\alpha$-lac and whey, prevented weight gain. Although the exact mechanism by which these proteins affect body weight is unclear, it may be related to the $\alpha$-lac component that demonstrated the ability to decrease weight in mice after diet-induced obesity ${ }^{(34,35)}$. Another pathway to body-weight regulation may be related to $\beta$-lactoglobulin, a principal component of whey, which was found to reduce both body-weight gain and adiposity in rats after a $25 \mathrm{~d}$ highprotein diet $^{(1)}$. In the present study, the weight-protective effects of the $\alpha$-lac and whey diets were observed, despite the volume of food consumption and running-wheel activity being diet-independent and similar in all animals.

Daily running-wheel activity, as well as its circadian rhythm, remained stable throughout the experiment. This result corroborates the findings shown previously in $\mathrm{C} 57 \mathrm{BL} / 6 \mathrm{~J}$ mice which held stable running-wheel activity, despite housing conditions, and may thus be regarded as a trait of the mouse line ${ }^{(36)}$. Running activity has a high rewarding potential and might compete with other positive reinforces such as ethanol $^{(37)}$ and drugs of abuse ${ }^{(36,38)}$. We hypothesised that if the running wheel has rewarding properties, then the returned access to the wheel after the short-term deprivation should increase the running activity. Although the activity did not differ between the diet groups after the returned access, casein-fed mice after the standard housing conditions only increased their activity when compared with their peers that continued in the enriched conditions. It might be suggested that the $\alpha$-lac and whey but not casein feeding exhibited compensative, or competitive, activity.

The differences might also be found due to the decreased activity of casein-fed mice under the enriched conditions. However, we have kept in mind that the $6 \mathrm{~h}$ returned running-wheel test was done on the next day after the individual and social test battery, which might have also influenced the running activity. In this case, neither the $\alpha$-lac nor the whey group demonstrated the changes in running activity. It means that casein anyway cannot compensate for stressful environmental effects while $\alpha$-lac and whey did. At the same time, whey and $\alpha$-lac had slight attractive properties according to the food preference test. It seems that food also might be considered as a competitive reward that reduced the rewarding potential of the running wheel. Orosco et al. ${ }^{(4)}$ showed that an $\alpha$-lac acute intervention decreased sucrose consumption, which has a high rewarding potential for mice. It seems that $\alpha$-lac compensated for it due to yet unclear mechanisms.

The decreased aggression towards other males, which was expected to come up after isolation ${ }^{(39)}$, might be explained by the presence of two rewarding stimuli, running wheel ${ }^{(40)}$ and attractive food that, probably, strongly suppressed aggressions $^{(41)}$. Whey-fed mice demonstrated more sociability in the male group and intended to contact with the hidden female more actively than casein-fed mice after the $30 \mathrm{~d}$ dietary intervention. Increased sexual behaviour is related usually to the increased blood testosterone level that was observed in CBA mice in the same behavioural situation ${ }^{(42)}$. The behaviour is also related to 5-HT1 receptors, because the antidepressant acutely increased sexuality while the repeated intervention resulted in minor conflicting effects ${ }^{(43)}$. Perhaps the whey-induced activity towards females could be related to $\beta$-lactoglobulin that forms equimolar complexes with 5-HT and the derivative of which has an affinity for 5-HT receptors ${ }^{(44)}$. On the other hand, concerning the forced swimming test, it does not appear that the 5-HT 
Table 4. Discriminant function coefficients of main behavioural elements that determine the behavioural function*

\begin{tabular}{|c|c|c|c|}
\hline \multirow[b]{2}{*}{ Test } & \multirow[b]{2}{*}{ Behaviour } & \multicolumn{2}{|c|}{ Coefficients } \\
\hline & & Function $1 \dagger$ & Function $2 \ddagger$ \\
\hline \multicolumn{4}{|c|}{ After $7 \mathrm{~d}$ enriched conditions } \\
\hline \multirow[t]{4}{*}{ Open field } & Locomotion through the centre (MD_1)§ & -0.968 & 0.020 \\
\hline & Locomotion around the perimeter (MD_1) & -0.170 & 0.800 \\
\hline & Contact with the new object (MD_2)§ & -0.328 & 0.556 \\
\hline & Freezing (TF_2) & 0.680 & -0.778 \\
\hline Light-dark box & Visits into the light compartment $(n)$ & 0.521 & 0.399 \\
\hline \multirow[t]{2}{*}{ Forced swimming } & Covered distance $(\mathrm{mm})$ & 1.616 & 0.145 \\
\hline & Movement (s) & -1.053 & 0.649 \\
\hline \multirow[t]{4}{*}{ Group test } & Non-aggressive contacts with group members (MD_1) & -0.291 & -0.690 \\
\hline & Aggression (MD_1) & 1.054 & -0.192 \\
\hline & Defence (MD_1) & 0.853 & 0.634 \\
\hline & Latency of non-aggressive contacts (s) & -0.746 & -0.419 \\
\hline \multicolumn{4}{|c|}{ After $7 \mathrm{~d}$ standard conditions } \\
\hline \multirow[t]{2}{*}{ Open field } & Locomotion through the centre (MD_1) & $1 \cdot 169$ & -0.262 \\
\hline & Locomotion around the perimeter (MD_1) & -0.620 & 0.417 \\
\hline Elevated-plus maze & Movement in the protected area $(s)$ & 1.951 & -0.845 \\
\hline \multirow[t]{2}{*}{ Forced swimming } & Covered distance $(\mathrm{mm})$ & 0.440 & 0.852 \\
\hline & Immobility (MD) & 1.883 & 0.023 \\
\hline \multirow[t]{2}{*}{ Group test } & Individual behaviour (RF) & 0.872 & 0.638 \\
\hline & Latency of non-aggressive contacts (s) & $-1 \cdot 144$ & $0 \cdot 163$ \\
\hline
\end{tabular}

MD, medial duration; TF, total frequency; RF, relative frequency.

${ }^{*}$ Coefficients of behavioural elements are presented to construct linear discriminant functions of behavioural profiles of the dietary groups. The coefficients were calculated by the discriminant function analysis based on individual and social behavioural measurements.

†Function 1 after the enriched conditions $=M D_{-} 1_{\mathrm{a}} \times(-0.968)+\mathrm{MD}_{-} 1_{\mathrm{b}} \times(-0.170)+\mathrm{MD} \_2_{\mathrm{c}} \times(-0.328)+\mathrm{TF} \_2 \mathrm{~d} \times 0.680+n_{\mathrm{e}} \times 0.521$ $+\mathrm{mm}_{\mathrm{f}} \times 1.616+s_{\mathrm{g}} \times(-1.053)+\mathrm{MD}_{\mathrm{h}} \times(-0.291)+\mathrm{MD}_{\mathrm{i}} \times 1.054+\mathrm{MD}_{\mathrm{j}} \times 0.853+s_{\mathrm{k}} \times(-0.746)$. Function 1 after the standard conditions $=$ MD $1, \times 1.169+\mathrm{MD} 1 \mathrm{~m} \times(-0.620)+s_{\mathrm{n}} \times 1.951+\mathrm{mm}_{\circ} \times 0.440+\mathrm{MD}_{\mathrm{p}} \times 1.883+\mathrm{RF}_{\mathrm{q}} \times 0.872+s_{\mathrm{r}} \times(-1.144)$.

‡Function 2 after the enriched conditions $=$ MD_1 $1 \mathrm{a} \times 0.20+\mathrm{MD} \_1_{\mathrm{b}} \times 0.800+\mathrm{MD} \_2_{\mathrm{c}} \times 0.556+\mathrm{TF} \_2 \mathrm{~d} \times(-0.778)+n_{\mathrm{e}} \times 0.399+\mathrm{mm} \mathrm{f} \times$ $0.145+s_{\mathrm{g}} \times 0.649+\mathrm{MD}_{\mathrm{h}} \times(-0.690)+\mathrm{MD}_{\mathrm{i}} \times(-0.192)+\mathrm{MD}_{\mathrm{j}} \times 0.634+s_{\mathrm{k}} \times(-0.419)$. Function 2 after the standard conditions $=$ MD_1 $\times(-0.262)+$ MD_1 $\mathrm{m} \times 0.417+s_{\mathrm{n}} \times(-0.845)+\mathrm{mm}_{\mathrm{o}} \times 0.852+\mathrm{MD}_{\mathrm{p}} \times 0.23+\mathrm{RF}_{\mathrm{q}} \times 0.638+s_{\mathrm{r}} \times 0.163$.

$\S 1$ and 2 , the first and second $3 \mathrm{~min}$ intervals that were specified for the open-field test where the observations were done (1) before and (2) after the installation of the new object.

system was activated. It suggests that the increased sexuality may be based on dopamine pathways ${ }^{(39)}$.

The results concerning individual behaviour appeared ambiguous from test to test, although the effects of diets were expected to show parallel results in different tests ${ }^{(25,26)}$. After the enriched conditions, $\alpha$-lac-fed mice were more anxious than casein-fed ones in the light-dark box test, while no differences between them were found in the open-field test. The results are in line with an earlier study: animals receiving $\alpha$-lac for nearly a week showed no differences in open-field behaviour compared with casein-fed ones ${ }^{(4)}$.

However, under the standard conditions, $\alpha$-lac-fed mice demonstrated less anxiety than casein-fed mice in the openfield test and less anxiety than their peers under the enriched conditions in the light-dark box test. The open-field test, as a more provocative test, produced more diet-specific differences than the light-dark box test. It supports the suggestion that a much more stressful situation or subjects more vulnerable to stress ${ }^{(45)}$ are necessary to indicate the mood-improving effects of the proteins in the post-feeding period. Such a conclusion was made in a human study in which an $\alpha$-lac diet was ineffective to produce changes in the emotional state of healthy women ${ }^{(9)}$.

The elevated-plus-maze test revealed that $\alpha$-lac- and wheyfed mice were more mobile than the casein group in the enriched conditions. A similar behavioural activity was shown in the animals exposed to a single meal of an $\alpha$-lac diet that visited the closed arms as well as the open arms more often than the animals receiving casein ${ }^{(4)}$. The increased mobility was found only in the protective area of the maze that is mostly associated with dopamine-induced locomotion ${ }^{(38)}$.

Depression-like status demonstrated by immobility was independent of the diets in the enriched conditions. In the standard conditions, whey-fed mice ceased to swim quicker than casein- and $\alpha$-lac-fed mice. However, all the animals under the standard conditions demonstrated a delay in immobility and swam longer than their peers in the enriched conditions. This is because the behaviour of whey-fed mice cannot be considered as a real depression-like state or worsened by the diet.

On the whole, all the animals under the enriched conditions appeared to be more anxious in the light-dark box test and displayed more depression-like behaviour in the force swimming test than mice in the standard conditions. Also, $\alpha$-lac- and whey-fed mice in the standard conditions showed less fear towards the new object in the open-field test than their peers under the enriched conditions. Perhaps the shortterm deprivation of the diet and the running wheel was not so dangerous but potentiated a searching activity. Mice that were intermittently withdrawn from food for a short time exhibited less anxiety and depressive behaviour than those regularly receiving food ${ }^{(18)}$. It seems that the shortterm deprivation of a palatable food or a rewarding item might increase the general searching activity (for the reward).

The anxiolytic-like activity of $\alpha$-lac may be related to the increased level of brain 5-HT that is typical for $\alpha$-lac-containing 
$\operatorname{diets}^{(6,8)}$. In an earlier study, such increased extracellular 5-HT level correlated with the behaviour of rats, which preferred a lighted compartment in the light-dark box test and demonstrated less immobility in the forced swimming test when compared with other animals whose 5-HT level was not changed $^{(46)}$. Regarding the brain pathways behind the behaviour followed by diets, it is difficult to explain the behaviour profiles only through the 5-HT activity. Thus, in one study ${ }^{(47)}$, $\beta$-lactoglobulin, a main component of the whey diet, has been shown to exhibit dopamine-dependent anxiolytic activity in the elevated-plus-maze test. It is possible that a delay in aggression observed in whey-fed mice after the standard conditions might be related to the functioning of the dopamine system. As mentioned previously, the activation of the dopamine system might also be responsible for the increased sexuality of whey-fed mice ${ }^{(48)}$.

In conclusion, all the diet groups demonstrated different behavioural profiles after a prolonged diet intervention. Thus, whey improved sociability while $\alpha$-lac exhibited anxiolytic and antidepressive activity. The mood-improving properties might be regarded as the behavioural profit of protein feeding that most probably correlates with different brain pathways, which need to be specified in future studies.

\section{Acknowledgements}

The present study was supported by the National Technology Agency (TEKES) of Finland and Valio Limited. K. P. and N. S. received funding from non-profit SalWe Limited, a Strategic Center for Health and Well-being Mind and Body research programme. The authors wish to thank the head of the institute of Biomedicine Professor Esa Korpi and also Pia Ollikainen, MSc (Valio Limited) for the protein compounds and Dr Elena Verbitskaya (Laboratory of Biomedical Statistics, Pavlov State Medical University, St Petersburg, Russia) for statistical consultations. O. Y. V., T. P. and R. K. designed the study. All the authors were involved in the reviewing and interpreting of the results and the writing of the manuscript. T. P. is employed by Valio Limited. All the other authors have no conflict of interest associated with the present study.

\section{References}

1. Wolfe AR, Arroyo C, Tedders SH, et al. (2011) Dietary protein and protein-rich food in relation to severely depressed mood: a 10 year follow-up of a national cohort. Prog Neuropsychopharmacol Biol Psychiatry 35, 232-238.

2. Markus CR (2008) Dietary amino acids and brain serotonin function; implications for stress-related affective changes. Neuromol Med 10, 247-258.

3. Heine W, Radke M, Wutzke KD, et al. (1996) Alphalactalbumin-enriched low-protein infant formulas: a comparison to breast milk feeding. Acta Paediatr 85, 1024-1028.

4. Orosco M, Rouch C, Beslot F, et al. (2004) Alphalactalbumin-enriched diets enhance serotonin release and induce anxiolytic and rewarding effects in the rat. Behav Brain Res 148, 1-10.

5. Markus CR, Olivier B, Panhuysen GE, et al. (2000) The bovine protein alpha-lactalbumin increases the plasma ratio of tryptophan to the other large neutral amino acids, and in vulnerable subjects raises brain serotonin activity, reduces cortisol concentration, and improves mood under stress. Am J Clin Nutr 71, 1536-1544.

6. Markus CR, Olivier B \& de Haan EH (2002) Whey protein rich in alpha-lactalbumin increases the ratio of plasma tryptophan to the sum of the other large neutral amino acids and improves cognitive performance in stress-vulnerable subjects. Am J Clin Nutr 75, 1051-1056.

7. Markus CR, Jonkman LM, Lammers JH, et al. (2005) Evening intake of alpha-lactalbumin increases plasma tryptophan availability and improves morning alertness and brain measures of attention. Am J Clin Nutr 81, 1026-1033.

8. Markus CR \& Jonkman LM (2007) Attention switching after dietary brain 5-HT challenge in high impulsive subjects. J Psychopharmacol 21, 700-708.

9. Scrutton H, Carbonnier A, Cowen PJ, et al. (2007) Effects of alpha-lactalbumin on emotional processing in healthy women. J Psychopharmacol 21, 519-524.

10. Eller LK \& Reimer RA (2010) Attenuation in weight gain with high calcium- and dairy-enriched diets is not associated with taste aversion in rats: a comparison with casein, whey, and soy. J Med Food 13, 1182-1188.

11. Pichon L, Potier M, Tome D, et al. (2008) High-protein diets containing different milk protein fractions differently influence energy intake and adiposity in the rat. Br J Nutr 99, 739-748

12. Kamemori N, Takeuchi T, Hayashida K, et al. (2004) Suppressive effects of milk-derived lactoferrin on psychological stress in adult rats. Brain Res 1029, 34-40.

13. Yan L, Demars LC \& Johnson LK (2012) Long-term voluntary running improves diet-induced adiposity in young adult mice. Nutr Res 32, 458-465.

14. Meeusen R (2005) Exercise and the brain: insight in new therapeutic modalities. Ann Transplant 10, 49-51.

15. Salomao EM \& Gomes-Marcondes MC (2012) Light aerobic physical exercise in combination with leucine and/or glutamine-rich diet can improve the body composition and muscle protein metabolism in young tumor-bearing rats. J Physiol Biochem 68, 493-501.

16. Mok E \& Thibault L (1999) Effect of diet textural characteristics on the temporal rhythms of feeding in rats. Physiol Behav 65, 893-899.

17. Yamamoto Y, Tanahashi T, Kawai T, et al. (2009) Changes in behavior and gene expression induced by caloric restriction in C57BL/6 mice. Physiol Genomics 39, 227-235.

18. Koot S, van den Bos R, Adriani W, et al. (2009) Gender differences in delay-discounting under mild food restriction. Behav Brain Res 200, 134-143.

19. Linden AM, Sandu C, Aller MI, et al. (2007) TASK-3 knockout mice exhibit exaggerated nocturnal activity, impairments in cognitive functions, and reduced sensitivity to inhalation anesthetics. J Pharmacol Exp Ther 323, 924-934.

20. Jansen F, Heiming RS, Kloke V, et al. (2011) Away game or home match: the influence of venue and serotonin transporter genotype on the display of offensive aggression. Behav Brain Res 219, 291-301.

21. Vekovischeva OY, Aitta-aho T, Verbitskaya E, et al. (2007) Acute effects of AMPA-type glutamate receptor antagonists on intermale social behavior in two mouse lines bidirectionally selected for offensive aggression. Pharmacol Biochem Behav 87, 241-249.

22. Vekovischeva OY, Aitta-Aho T, Echenko O, et al. (2004) Reduced aggression in AMPA-type glutamate receptor GluR-A subunit-deficient mice. Genes Brain Behav 3 $253-265$. 
23. Macbeth AH, Edds JS, Young WS, et al. (2009) Housing conditions and stimulus females: a robust social discrimination task for studying male rodent social recognition. Nat Protoc 4, 1574-1581.

24. Miyazaki S, Tanebe K, Sakai M, et al. (2002) Interleukin 2 receptor gamma chain (gamma(c)) knockout mice show less regularity in estrous cycle but achieve normal pregnancy without fetal compromise. Am J Reprod Immunol 47, 222-230.

25. Nyberg JM, Vekovischeva O \& Sandnabba NK (2003) Anxiety profiles of mice selectively bred for intermale aggression. Behav Genet 33, 503-511.

26. Ramos A (2008) Animal models of anxiety: do I need multiple tests? Trends Pharmacol Sci 29, 493-498.

27. Rogers DC, Fisher EM, Brown SD, et al. (1997) Behavioral and functional analysis of mouse phenotype: SHIRPA, a proposed protocol for comprehensive phenotype assessment. Mamm Genome 8, 711-713.

28. Castagne V, Porsolt RD, Moser P, et al. (2009) Use of latency to immobility improves detection of antidepressant-like activity in the behavioral despair test in the mouse. Eur J Pharmacol 616, 128-133.

29. Hedou G, Pryce C, Di Iorio L, et al. (2001) An automated analysis of rat behavior in the forced swim test. Pharmacol Biochem Behav 70, 65-76.

30. Clark TG, Bradburn MJ, Love SB, et al. (2003) Survival analysis part I: basic concepts and first analyses. Br J Cancer $\mathbf{8 9}$, $232-238$

31. Leighty RE, Nilsson LN, Potter H, et al. (2004) Use of multimetric statistical analysis to characterize and discriminate between the performance of four Alzheimer's transgenic mouse lines differing in Abeta deposition. Behav Brain Res 153, 107-121

32. Vekovischeva OY, Verbitskaya EV, Aitta-Aho T, et al. (2007) Multimetric statistical analysis of behavior in mice selected for high and low levels of isolation-induced male aggression. Behav Processes 75, 23-32.

33. Chadman KK, Yang M \& Crawley JN (2009) Criteria for validating mouse models of psychiatric diseases. Am J Med Genet B Neuropsychiatr Genet 150B, 1-11.

34. Pilvi TK, Harala S, Korpela R, et al. (2009) Effects of highcalcium diets with different whey proteins on weight loss and weight regain in high-fat-fed C57BL/6J mice. Br J Nutr 102, $337-341$.

35. Tauriainen E, Storvik M, Finckenberg P, et al. (2011) Skeletal muscle gene expression profile is modified by dietary protein source and calcium during energy restriction. J Nutrigenet Nutrigenomics 4, 49-62.

36. de Visser L, van den Bos R, Stoker AK, et al. (2007) Effects of genetic background and environmental novelty on wheel running as a rewarding behaviour in mice. Behav Brain Res 177, 290-297.

37. Ozburn AR, Harris RA \& Blednov YA (2008) Wheel running, voluntary ethanol consumption, and hedonic substitution. Alcohol 42, 417-424.

38. El Rawas R, Thiriet N, Lardeux V, et al. (2009) Environmental enrichment decreases the rewarding but not the activating effects of heroin. Psychopharmacology 203, 561-570.

39. Matsumoto K, Pinna G, Puia G, et al. (2005) Social isolation stress-induced aggression in mice: a model to study the pharmacology of neurosteroidogenesis. Stress $\mathbf{8}, 85-93$.

40. Couppis MH \& Kennedy CH (2008) The rewarding effect of aggression is reduced by nucleus accumbens dopamine receptor antagonism in mice. Psychopharmacology 197, $449-456$.

41. de Almeida RM, Ferrari PF, Parmigiani S, et al. (2005) Escalated aggressive behavior: dopamine, serotonin and GABA. Eur J Pharmacol 526, 51-64.

42. Popova NK \& Amstislavskaya TG (2002) Involvement of the 5-HT(1A) and 5-HT(1B) serotonergic receptor subtypes in sexual arousal in male mice. Psychoneuroendocrinology 27, 609-618.

43. Haensel SM \& Slob AK (1997) Flesinoxan: a prosexual drug for male rats. Eur J Pharmacol 330, 1-9.

44. Taheri-Kafrani A, Choiset Y, Faizullin DA, et al. (2011) Interactions of beta-lactoglobulin with serotonin and arachidonyl serotonin. Biopolymers 95, 871-880.

45. Markus CR, Firk C, Gerhardt C, et al. (2008) Effect of different tryptophan sources on amino acids availability to the brain and mood in healthy volunteers. Psychopharmacology 201, 107-114.

46. Mechan AO, Fowler A, Seifert N, et al. (2011) Monoamine reuptake inhibition and mood-enhancing potential of a specified oregano extract. Br J Nutr 105, 1150-1163.

47. Hou IC, Suzuki C, Kanegawa N, et al. (2011) Beta-lactotensin derived from bovine beta-lactoglobulin exhibits anxiolyticlike activity as an agonist for neurotensin NTS(2) receptor via activation of dopamine $\mathrm{D}(1)$ receptor in mice. J Neurochem 119, 785-790.

48. Hull EM \& Dominguez JM (2007) Sexual behavior in male rodents. Horm Behav 52, 45-55. 